\title{
Repeatability Data and Agreement of Keratometry With the VERION System Compared to the IOLMaster
}

Gabor Nemeth, MD, PhD; Eszter Szalai, MD, PhD; Ziad Hassan, MD, PhD; Agnes Lipecz, MD; Andras Berta, MD, PhD, DSc; Laszlo Modis, Jr., MD, PhD, DSc

\section{ABSTRACT}

PURPOSE: To analyze the repeatability of keratometric and white-to-white (WTW) distance measurements with the VERION Measurement Module (Alcon Laboratories, Inc., Fort Worth, TX) and to compare the measured data to the results of the IOLMaster (Carl Zeiss Meditec, Jena, Germany).

METHODS: Three images were captured with the VERION and the flattest and steepest keratometric data, the astigmatism axis, and the WTW distance were recorded. Subsequently, the axial length, the keratometric data with axis, and the WTW distance were measured with an IOLMaster. The repeatability data of the keratometric value of the VERION System, converted to cross cylinder $\mathrm{J}_{0}$ and $\mathrm{J}_{45}$ vector components, were analyzed. The agreement data for keratometry obtained by the VERION System and the differences regarding keratometric data and WTW distance compared to IOLMaster were calculated.

RESULTS: The measurements were conducted in 50 eyes of 50 healthy volunteers (median age: 50.32 years, range: 19.34 to 85.3 years). The flattest and the steepest keratometric data, the diopter of astigmatism, the $\mathrm{J}_{0}$ and $\mathrm{J}_{45}$ vector components, and WTW distance did not differ significantly between devices $(P$ $>$.05). Intraclass correlation coefficients (range: 0.863 to 0.994 ) and Cronbach's alpha values (range: 0.950 to 0.998 ) were high for all parameters measured by the VERION System.

CONCLUSIONS: The VERION System has high repeatability and agreement with the IOLMaster, making it suitable as an alternative tool in clinical practice.

[J Refract Surg. 2015;31(5):333-337.]

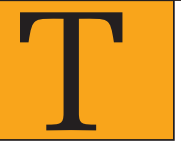

he exact measurement of the radius of the curvature of the cornea is crucial for planning the diopter of the intraocular lenses (IOLs) for implantation during cataract surgery. The error in measurements of the keratometric data can lead to unwanted postoperative refractive error. Although keratometric mistakes are not the first or most frequent source of error in today's biometric methods, ${ }^{1}$ keratometry has an undisputed and important role in cataract surgery. Moreover, cases of implantation of toric IOLs require more precise keratometric readings and cylinder axis determination than ever before.

There are numerous papers showing that the repeatability of keratometric measurements is excellent in the case of the IOLMaster (Carl Zeiss Meditec, Jena, Germany), ${ }^{2-4}$ although above 42.0 diopters (D), the cylinder axis has relatively low repeatability data. ${ }^{2}$ In the case of the Lenstar (Haag-Streit, Koeniz, Switzerland), the interclass coefficient of the variation of the astigmatism axis was 0.915 and the mean arithmetic difference between the two measurement sessions was $3.19^{\circ}$, with an absolute difference of a median of $9^{\circ} .{ }^{5}$ The Lenstar keratometry has repeatable values, ${ }^{6,7}$ but according to Zhao et al., ${ }^{7}$ the Lenstar and the IOLMaster cannot be used interchangeably in relation to keratometric data. With regard to average keratometric data, it seems that the Lenstar is biometrically equivalent to the IOLMaster, ${ }^{8}$ and the correlation between the cylinder axis measurements of the IOLMaster and the Lenstar is high. ${ }^{9}$ However, Rohrer et al. ${ }^{9}$ observed that the differences between the axis value of the flattest meridian in the Lenstar and the IOLMaster in a large percentage of patients is unacceptably high. Besides these controversial

From the Department of Ophthalmology, University of Debrecen, Debrecen, Hungary (GN, ES, $A L, A B, L M)$; and Orbi-Dent Health and Laser Center, Debrecen, Hungary $(\mathrm{ZH})$.

Submitted: October 11, 2014; Accepted: April 2, 2015

The authors have no financial or proprietary interest in the materials presented herein.

Correspondence: Gabor Nemeth, MD, PhD, Department of Ophthalmology, University of Debrecen, Nagyerdei blvd. 98, 4012 Debrecen, Hungary. E-mail: nemeth222@yahoo.com

doi:10.3928/1081597X-20150424-01 


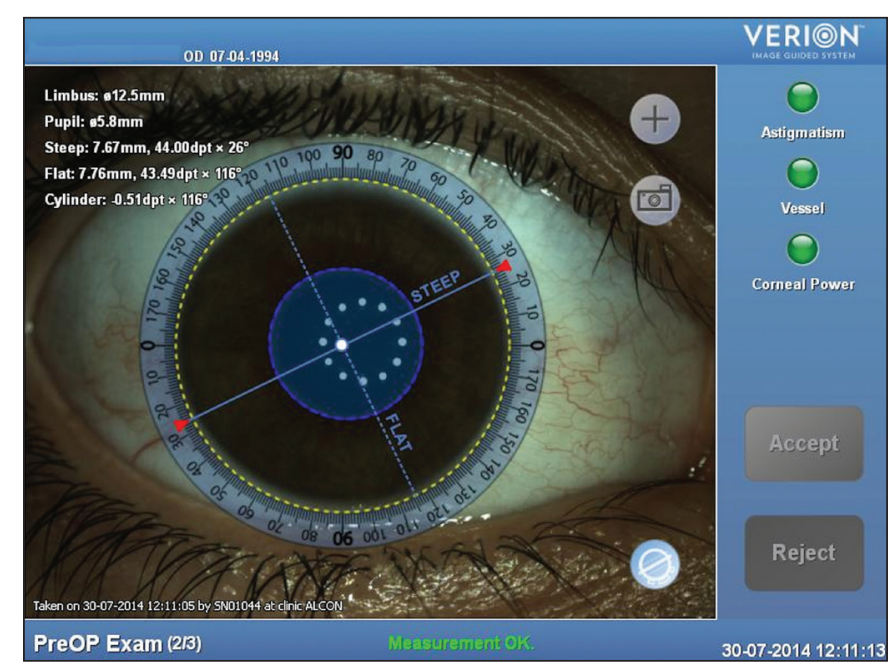

Figure 1. A demonstrative picture taken by the Measurement Module of the VERION Image Guided System (Alcon Laboratories, Inc., Fort Worth, TX). The keratometry data for axis, pupil diameter and limbus diameter are recorded with the help of a high definition picture.

results, these two devices are now the biometric standard in keratometry and, of course, in planning the diopter of the IOLs for cataract surgery.

Recently, a new system arrived on the market, intended to provide a complete preoperative and postoperative assessment, called the "VERION Image Guided System" (Alcon Laboratories Inc., Fort Worth, TX). With this new system, a question is raised according to the reproducibility of its keratometric and white-towhite (WTW) distance measurements, and the differences in the data obtained by this new system and the standard ones.

Our aim was to analyze the repeatability of this new biometric and analysis system. Another aim was to assess the keratometric and WTW distance measurements and the differences between the VERION System and the IOLMaster regarding these data.

\section{PATIENTS AND METHODS}

The VERION Image Guided System (with software version 2.5, February 12, 2014) consists of the Reference Unit and the Digital Marker. The Reference Unit comprises the Measurement Module and the Vision Planner; with the latter, we can plan the surgery steps, including IOL calculation, and the postoperative measurements data can be analyzed using it. The Digital Marker was constructed to aim for the most precise refractive outcomes of cataract surgeries, for use in the operating room. In particular, with the Reference Unit, we can measure the biometric parameters of the eye (the keratometry, limbus position and diameter, pupil position and diameter, and corneal reflex position, although not the anterior chamber depth or axial length), and can help plan surgical data (eg, the localization of corneal incisions and the placing of the limbal relaxing incisions for astigmatism management).

The system provides digital, high-definition imaging of the surrounding vessels, and the limbus and iris features of the patient in a sitting position (called "registration"), which are then used for intraoperative tracking in patients lying down and for automatic correction of the cyclotorsional rotation of the eye. The measured data are transferred to the Digital Marker with the help of a USB stick. In the operating room, the surgeon can see a live, real-time tracking overlay picture in the right or left ocular of the supported operating microscope and obtain image guides for corneal incisions, capsulorhexis, IOL centration, and IOL alignment in the case of toric IOL. Additionally, the System can calculate surgically induced astigmatism and can optimize the IOL constant if the patient has a postoperative followup and repeated measurements taken by this system.

The exclusion criteria were an absolute spherical equivalent of refractive error of greater than $3.0 \mathrm{D}$ and any anterior segment disease or contact lens wearing. Volunteers were in a seated position with their chin on the chinrest and their forehead against the Measurement Module. First, with the help of a joystick, the examiner targets a marker on the center of the cornea, thus enabling the patients to see a red circle of light at which they must look. The adjustment of direction we need to move the device is shown on the screen as arrows. During the adjustment, infrared photos are taken and a green circle immediately appears in the center of the cornea. At that moment, the examiner must push the button on the joystick to take a snapshot. During the adjustment, four signals appear on the monitor, called "Centration," "Corneal Power," "Focus," and "Fixation"; if these are shown in green, the setting is accurate. On the completed snapshots, three signals are displayed, namely "Astigmatism," "Vessel," and "Corneal Power," which aim to quantify the current picture (Figure 1). The measurement procedure was repeated three times by the same physician in our patients, and all of the measurement data (steep and flat radius of curvature of the cornea [mm], cylinder diopter [D], flat axis degree, and limbus diameter) were recorded and exported to an Excel spreadsheet (Microsoft Corporation, Redmond, WA) for repeatability calculations. During the time between the three snapshots, the patients could move their chins from the chinrest. After taking the three snapshots, the examiner had to choose one of the pictures to save, which could then be exported from the Planner. The Measurement Module uses $1.3375 \mathrm{~mm}$ as a refractive index for keratometry. The keratometry measurement takes approximately 20 
seconds, in which more than 300 infrared pictures are taken, and a total of more than 1,000 data points are recorded for further averaging.

Subsequently, ocular biometric parameters (axial length with a signal/noise ratio of at least 10.0, and keratometric data) were recorded with the IOLMaster (software version 5.4.3.0002). The IOLMaster measures the radius of the curvature of the anterior corneal surface $2.5 \mathrm{~mm}$ from the center in one zone at six fixed points in a hexagonal pattern, with five readings per point acquired for each measurement. The measurements are performed automatically and the device uses an LED light of $880 \mathrm{~nm}$ for illumination for keratometric measurement and one of $590 \mathrm{~nm}$ for measuring the WTW distance.

Statistical analysis was performed using MedCalc for Windows, version 12.2.1 (MedCalc Software, Ostend, Belgium) and the Microsoft Excel software. For continuous variables, the results were written as median, 95\% confidence interval (95\% CI) for the median and ranges. The normality of the data was tested using the Kolmogorov-Smirnov test. If the normality was rejected $(P<.05)$, non-parametric tests were used. The Wilcoxon signed-rank test was used for comparing paired groups of data, and Spearman's correlation coefficients $(r)$ were calculated to describe the relationship between non-parametric data groups. Jackson's cross cylinder power vector components $\left(\mathrm{J}_{0}\right.$ and $\mathrm{J}_{45}$ ) were calculated with the method described by Thibos et al., ${ }^{10}$ and differences in vector components between the devices were analyzed. For repeatability calculation, the intraclass correlation coefficient (ICC) (as intra-session repeatability), its $95 \%$ CI value, and the value of Cronbach's alpha (as the internal consistency of the data) were determined. A $P$ value less than .05 was considered to be statistically significant. Bland-Altman graphs were created to describe the agreement between devices, and the $95 \%$ limits of agreement were calculated and visualized as the mean \pm 1.95 standard deviation of the difference. All of the patients were informed about the course and the aim of the measurements. The protocol adhered to the tenets of the Declaration of Helsinki and was approved by the local ethics committee.

\section{RESULTS}

The measurements were conducted in 50 eyes of 50 healthy volunteers (median age: 50.32 years, $95 \%$ CI for the median: 37.26 to 58.06 years, range: 19.34 to 85.30 years). The keratometric data and corneal WTW data measured by the VERION System and the IOLMaster are shown in detail in Table 1. Twenty-seven eyes had greater than $0.75 \mathrm{D}$ and 21 eyes had greater than 1.0 $\mathrm{D}$ of corneal astigmatism measured by VERION. The

\begin{tabular}{|c|c|c|c|}
\hline \multicolumn{4}{|c|}{$\begin{array}{c}\text { TABLE } 1 \\
\text { Descriptive Statistical Results of } \\
\text { Keratometric Data and Corneal } \\
\text { Diameter Obtained by the VERION } \\
\text { System and the IOLMastera }\end{array}$} \\
\hline Parameter & VERION System & IOLMaster & $P$ \\
\hline $\begin{array}{l}\text { Flattest kerato- } \\
\text { metric data (D) }\end{array}$ & 43.52 & 43.41 & .15 \\
\hline $95 \% \mathrm{Cl}$ & 42.87 to 43.88 & 42.64 to 43.92 & \\
\hline Range & 39.20 to 47.40 & 39.11 to 47.47 & \\
\hline $\begin{array}{l}\text { Steepest kerato- } \\
\text { metric data (D) }\end{array}$ & 44.59 & 44.38 & .66 \\
\hline $95 \% \mathrm{Cl}$ & 44.09 to 45.24 & 44.12 to 45.12 & \\
\hline Range & 40.81 to 48.77 & 40.81 to 48.56 ) & \\
\hline $\begin{array}{l}\text { Average kerato- } \\
\text { metric data (D) }\end{array}$ & 43.82 & 43.89 & .62 \\
\hline $95 \% \mathrm{Cl}$ & 43.54 to 44.54 & 43.65 to 44.48 & \\
\hline Range & 40.01 to 47.94 & 39.96 to 48.01 & \\
\hline Astigmatism (D) & 0.84 & 0.93 & .53 \\
\hline $95 \% \mathrm{Cl}$ & 0.65 to 1.03 & 0.69 to 1.15 & \\
\hline Range & 0.12 to 4.71 & 0.20 to 4.61 & \\
\hline$J_{0}(D)$ & 0.28 & 0.27 & .08 \\
\hline $95 \% \mathrm{Cl}$ & 0.12 to 0.34 & 0.14 to 0.42 & \\
\hline Range & -2.08 to 1.46 & -2.14 to 1.56 & \\
\hline $\mathrm{J}_{45}(\mathrm{D})$ & -0.04 & -0.07 & .82 \\
\hline $95 \% \mathrm{Cl}$ & -0.16 to 0.03 & -0.12 to 0.00 & \\
\hline Range & -1.08 to 0.42 & -0.86 to 0.44 & \\
\hline WTW (mm) & 12.20 & 12.10 & .07 \\
\hline $95 \%$ C & 12.02 to 12.43 & 11.90 to 12.30 & \\
\hline Range & 11.57 to 13.20 & 11.33 to 13.00 & \\
\hline $\begin{array}{l}D=\text { diopters; } J_{0}=J \\
O^{\circ} \text { and } 90^{\circ} ; J_{45}=J a \\
45^{\circ} \text { and } 135^{\circ} ; \text { WTW } \\
\text { aThe results are desc } \\
\text { median }(95 \% \text { CI) and } \\
\text { The VERION System } \\
\text { Worth, TX, and the IO }\end{array}$ & $\begin{array}{l}\text { on's cross cylinder } p \\
\text { n's cross-cylinder po } \\
\text { orizontal white-to-wh } \\
d \text { as median, } 95 \% \text { cc } \\
\text { ges. } \\
\text { anufactured by Alcon } \\
\text { aster by Carl Zeiss M }\end{array}$ & $\begin{array}{l}\text { Wer vector compone } \\
\text { wer vector compones } \\
\text { te distance } \\
\text { infidence interval for } \\
\text { Laboratories, Inc., } \\
\text { editec, Dublin, CA. }\end{array}$ & $\begin{array}{l}\text { at axis } \\
t \text { axis }\end{array}$ \\
\hline
\end{tabular}

axial length was a median of $23.51 \mathrm{~mm}$ (95\% CI for the median: 23.12 to $23.93 \mathrm{~mm}$, range: 21.39 to $25.36 \mathrm{~mm}$ ) measured with the IOLMaster.

The measurement repeatability characterized by ICC, 95\% CI for ICC, Cronbach's alpha, and a 95\% lower confidence limit of Cronbach's alpha were high for all parameters obtained by the VERION Measurement Module (Table 2). If we separated our patients into low cylinder $(\leq 1.0 \mathrm{D})$ and high cylinder $(>1.0 \mathrm{D})$ groups, neither the repeatability data of the VERION System (all $P>.2$ ) nor the axis difference between the VERION System and the IOLMaster $(P=.58)$ was significantly different between these two groups. 
TABLE 2

Repeatability Data of Corneal Data Obtained by the VERION Image Guided System

\begin{tabular}{|c|c|c|c|c|}
\hline Parameter & ICC & $95 \% \mathrm{Cl}$ of ICC & Cronbach's alpha & 95\% Lower Confidence Limit of Cronbach's alpha \\
\hline VERION K1 (D) & 0.975 & $0.960-0.984$ & 0.992 & 0.988 \\
\hline VERION K2 (D) & 0.970 & $0.953-0.982$ & 0.990 & 0.985 \\
\hline VERION astigmatism (D) & 0.973 & $0.957-0.983$ & 0.991 & 0.987 \\
\hline VERION flat axis (degrees) & 0.994 & 0.991-0.996 & 0.998 & 0.997 \\
\hline VERION J & 0.977 & $0.964-0.986$ & 0.992 & 0.988 \\
\hline VERION J ${ }_{45}(\mathrm{D})$ & 0.946 & $0.915-0.967$ & 0.982 & 0.973 \\
\hline VERION WTW (mm) & 0.863 & $0.792-0.914$ & 0.950 & 0.926 \\
\hline
\end{tabular}

ICC = intraclass coefficient of variation; $95 \% \mathrm{Cl}=95 \%$ confidence interval; $\mathrm{K} 1$ = keratometric data on the flattest corneal meridian; $\mathrm{K} 2=\mathrm{keratometric} \mathrm{data} \mathrm{on}$ the steepest corneal meridian; $J_{0}$ and $J_{45}=$ power vector components of Jackson's cross cylinder; WTW $=$ white-to-white distance; $D=$ diopters

The VERION System is manufactured by Alcon Laboratories, Inc., Fort Worth, TX.

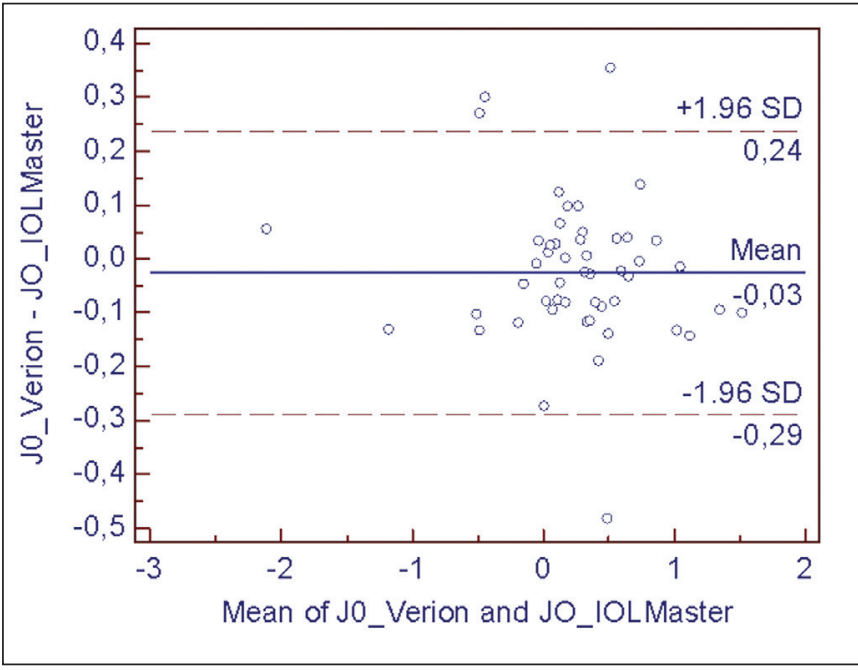

Figure 2. Difference in Jackson $J_{0}$ power vector components between the VERION System (Alcon Laboratories, Inc., Fort Worth, TX) and the IOLMaster (Carl Zeiss Meditec, Jena, Germany) against their mean (Bland-Altman plot).

The differences between the $\mathrm{J}_{0}$ power vector component of the VERION System and the IOLMaster had a mean of $-0.03 \mathrm{D}$ (95\% CI for the mean: -0.08 to $0.01 \mathrm{D}$, range: -0.48 to $0.35 \mathrm{D}$ ). Regarding the $\mathrm{J}_{45}$ vector component, the difference had a mean of $-0.006 \mathrm{D}(95 \%$ CI for the mean: -0.03 to $0.02 \mathrm{D}$, range: -0.35 to $0.29 \mathrm{D}$ ). The difference regarding the axis of astigmatism between the VERION System and the IOLMaster (the IOLMaster's steepest axis subtracted from VERION's steepest axis) had a median of $-1.0^{\circ}$ ( $95 \%$ CI for the median: -2.39 to $0.00^{\circ}$; range: $-21^{\circ}$ to $29^{\circ}$ ). All eyes with more than $15^{\circ}$ of disagreement between devices (four eyes) had a cylinder value less than $1.0 \mathrm{D}$.

Regarding the WTW distance, the difference was a mean of $0.13 \mathrm{~mm}$ (95\% CI for the mean: 0.09 to 0.20 $\mathrm{mm}$, range: -0.10 to $0.60 \mathrm{~mm}$ ) between these two devices. The limits of agreement were -0.29 to $0.24 \mathrm{D}$ for the $\mathrm{J}_{0}$ vector components, -0.20 to $0.19 \mathrm{D}$ for the $\mathrm{J}_{45}$ vector

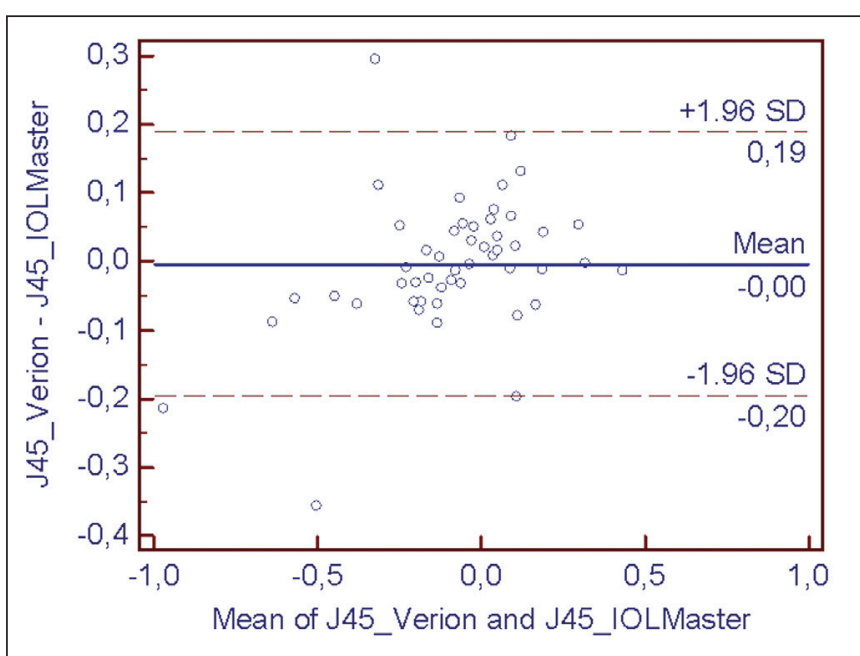

Figure 3. Difference in Jackson $J_{45}$ power vector components between the VERION System (Alcon Laboratories, Inc., Fort Worth, TX) and the IOLMaster (Carl Zeiss Meditec, Jena, Germany) against their mean (Bland-Altman plot).

components, and -0.14 to $0.42 \mathrm{~mm}$ for the WTW values (Bland-Altman graphs, Figures 2-4).

The correlation between the $\mathrm{J}_{0}$ power vector components calculated from data of the VERION System and the IOLMaster was $r=0.949(P<.001)$. This correlation was $r=0.945(P<.001)$ regarding the $\mathrm{J}_{45}$ power vector component. In the case of the WTW values, the correlation was $r=0.930(P<.001)$ between the tested devices. The correlation between the axial length of the eyes and the differences for the two studied devices was $r=$ $0.070(P=.60)$ for the $\mathrm{J}_{0}$ power vector components and $r=0.304(P=.03)$ for the $\mathrm{J}_{45}$ power vector components.

\section{DISCUSSION}

Assessing the reproducibility of keratometry is a popular topic in the ophthalmological literature and it plays an important role in implementing any new system, device, or technique in clinical practice. Because 


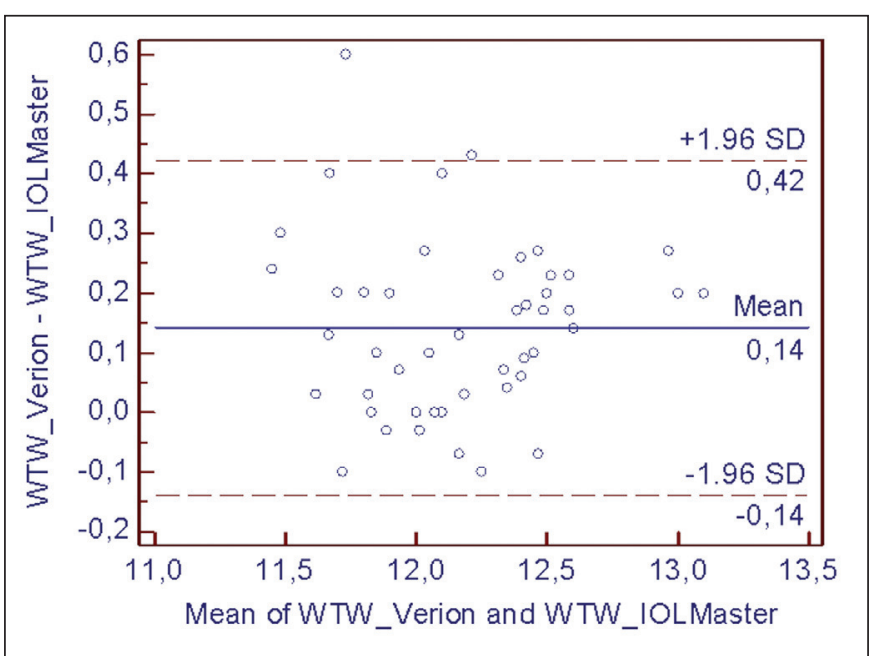

Figure 4. Difference in white-to-white (WTW) value between the VERION System (Alcon Laboratories, Inc., Fort Worth, TX) and the IOLMaster (Carl Zeiss Meditec, Jena, Germany) against their mean (Bland-Altman plot).

the VERION System measures keratometric data with high repeatability—according to our findings—it may enjoy an increasing role in today's cataract surgery, especially in cases of toric IOL implantations. Although the disagreement in the steepest corneal meridian between the two devices tested by us was not negligible in a few eyes (ie, up to $29^{\circ}$ ), most of the patients showed a clinically insignificant difference in keratometric power vectors between the two optical devices. The few outliers (which are visible in our $\mathrm{J}_{0}$ and $\mathrm{J}_{45}$ Bland-Altman plots) showed an astigmatism axis difference that was higher than acceptable between the new VERION System and the IOLMaster. These eyes did not have large keratometric or cylinder values, and the axial lengths were average. This fact draws attention to the fact that these two devices sometimes measured different parameters and, in these cases, a question is raised as to which data are to be preferred for further calculation. Only postoperative results can answer this question, given that keratometry therefore is a problematic point in ophthalmology. Besides this, further studies will require the analysis of keratometric repeatability data on a larger number of eyes with high corneal astigmatism.

One remarkable disadvantage of the VERION System is that posterior corneal surface measurement is not possible; this may have a significant role in a relatively high percentage of the patients, especially those waiting for toric IOL implantation. ${ }^{11}$ Another disadvantage of the system is that another tool measuring the axial length is required for the completion of the calculations for cataract surgery (ie, IOL diopter planning).

The WTW distance measurements have a role in phakic IOL implantation ${ }^{12}$ and in a fourth-generation biometric formula (Holladay 2). ${ }^{13}$ Thus, its measurements also have clinical importance. With the new VERION Image Guided System, the reproducibility of the WTW distance was high, and the difference was clinically insignificant in most of the studied eyes compared to the IOLMaster.

A novel method for keratometric and WTW distance evaluation, called the "VERION Image Guided System", exhibits high measurement repeatability for all obtained parameters and shows high correlations with the data of the IOLMaster. It is a new method that has the potential to be an alternative keratometric and complete assessment tool in ophthalmological practice.

\section{AUTHOR CONTRIBUTIONS}

Study concept and design (GN, AB, LM); data collection (GN, ES, $Z H, A L)$; analysis and interpretation of data (GN); writing the manuscript (GN, ES); critical revision of the manuscript ( $Z H, A L, A B, L M$ ); statistical expertise (GN); supervision ( $A B, L M)$

\section{REFERENCES}

1. Olsen T. Calculation of intraocular lens power: a review. Acta Ophthalmol Scand. 2007;85:472-485.

2. Shammas HJ, Chan S. Precision of biometry, keratometry, and refractive measurements with a partial coherence interferometrykeratometry device. J Cataract Refract Surg. 2010;36:1474-1478.

3. Srivannaboon S, Chirapapaisan C, Chonpimai P, Koodkaew S. Comparison of ocular biometry and intraocular lens power using a new biometer and a standard biometer. J Cataract Refract Surg. 2014;40:709-715.

4. Dulku S, Smith HB, Antcliff RJ. Keratometry obtained by corneal mapping versus the IOLMaster in the prediction of postoperative refraction in routine cataract surgery. Clin Experiment Ophthalmol. 2013;41:12-18.

5. Shammas HJ, Hoffer KJ. Repeatability and reproducibility of biometry and keratometry measurements using a noncontact optical low-coherence reflectometer and keratometer. Am J Ophthalmol. 2012;153:55-61.

6. Cruysberg LP, Doors M, Verbakel F, Berendschot TT, De Brabander J, Nuijts RM. Evaluation of the Lenstar LS 900 noncontact biometer. Br J Ophthalmol. 2010;94:106-110.

7. Zhao J, Chen Z, Zhou Z, Ding L, Zhou X. Evaluation of the repeatability of the Lenstar and comparison with two other non-contact biometric devices in myopes. Clin Exp Optom. 2013;96:92-99.

8. Jasvinder S, Khang TF, Sarinder KK, Loo VP, Subrayan V. Agreement analysis of LENSTAR with other techniques of biometry. Eye (Lond). 2011;25:717-724.

9. Rohrer K, Frueh BE, Wälti R, Clemetson IA, Tappeiner C, Goldblum D. Comparison and evaluation of ocular biometry using a new noncontact optical low-coherence reflectometer. Ophthalmology. 2009;116:2087-2092.

10. Thibos LN, Wheeler W, Horner D. Power vectors: an application of Fourier analysis to the description and statistical analysis of refractive error. Optom Vis Sci. 1997;74:367-375.

11. Koch DD, Jenkins RB, Weikert MP, Yeu E, Wang L. Correcting astigmatism with toric intraocular lenses: effect of posterior corneal astigmatism. J Cataract Refract Surg. 2013;39:1803-1809.

12. Lovisolo CF, Reinstein DZ. Phakic intraocular lenses. Surv Ophthalmol. 2005;50:549-587.

13. Hoffer KJ. Clinical results using the Holladay 2 intraocular lens power formula. J Cataract Refract Surg. 2000;26:1233-1237. 